\title{
A Case Study of the Joint Program between Shenzhen Polytechnic and City University of Seattle
}

\author{
Meng Xiao"
}

School of Management, Shenzhen Polytechnic, Shenzhen, China

DOI: $10.36347 /$ sjahss.2020.v08i07.007

| Received: 30.06.2020 | Accepted: 08.07.2020 | Published: 30.07.2020

*Corresponding author: Meng Xiao

Abstract

Review Article

With the rapid development of economic globalization, interdisciplinary talents are strongly needed in the coming future. Therefore, education should do adjustments to the demands of society. International cooperation is an educational means that is employed by most of colleges and universities in China. This paper takes the joint program between Shenzhen Polytechnic and City University of Seattle as an example, introduces its talents cultivation mode, and is in hope of affording related experience to other international cooperation programs to come.

Keywords: International cooperation, joint program, Shenzhen Polytechnic, City University of Seattle.

Copyright @ 2020: This is an open-access article distributed under the terms of the Creative Commons Attribution license which permits unrestricted use, distribution, and reproduction in any medium for non-commercial use (NonCommercial, or CC-BY-NC) provided the original author and source are credited.

\section{INTRODUCTION}

To meet the growing demands of interdisciplinary talents in Shenzhen, School of Management from Shenzhen Polytechnic ("SZPT") and School of Management from City University of Seattle ("CityU") launched a joint program of logistics management in 2012 to cultivate interdisciplinary logistics management talents [1].

Economic and Social Background for Selection of Logistics Management

As one of top four pillar industries in Shenzhen, logistics industry plays a significant role in the economic structure of Shenzhen. The international development of Shenzhen calls for innovative and versatile talents with high quality and skills and international visions, who are proficient in foreign languages and familiar with international rules [2].

Logistics management of SZPT has been listed in the establishment programs of higher vocational colleges funded by the central finance in 2012 for its remarkable strength. It is a demonstration major in vocational college of Guangdong Province, and also a major to be established in national program to "improve the capabilities of higher vocational colleges in professional service and industry development". A long-term cooperation has been created with logistics enterprises as China Overseas Logistics, COSCO Logistics, Shenzhen Chiwan Wharf Holdings Co., Ltd. and ZJS Express [3].
Joint program of logistics management between SZPT and CityU is an effective channel to cultivate Chinese and foreign interdisciplinary talents. This will realize mutual complementary of superior resources of both parties, promote talent cultivation quality of our logistics management, and meet Shenzhen's need for international high-skill logistics talents [4].

\section{Nature, Level, and Certificate}

The joint program for Logistics Management (Sino-US cooperation) between SZPT and CityU is a non-independent school-running education program at college level approved by the Education Department of Guangdong Province. Students meeting graduation conditions with required credits can obtain certificate of graduation of SZPT and the basic education and management certificate of CityU (a qualification certificate directly linked to the bachelor degree of CityU) [5].

\section{Culture, Quality, and Level of CityU}

City University of Seattle is a private institution that offers educations at doctor, master and associate bachelor degree.

CityU has good school-running quality and level among private and non-profit higher educational institutions in US, and is accredited from the Northwest Commission on Colleges and Universities (NWCCU). 
The School of Management of CityU was accredited by the International Assembly for Collegiate Business Education (IACBE) from March 2000 to March 2010, and is an official candidate of the Accreditation Council for Business Schools and Programs (ACBSP). CityU's Computer Systems and Information Systems are two majors with most applicants and highest employment rates [6].

CityU attracts SZPT for its high professional level, advanced educational ideas and rich educational resources. It is the only college with 11 overseas campus projects in Washington State and receives highest proportion of international students in the northwest of US. Over 1,500 students have been graduated from its MBA programs in China over the past 14 years. CityU and Boeing Company have jointly held MBA programs for China National Aviation Corporation, Civil Aviation Administration of China and National Development and Reform Commission for successive 8 years, and cultivated 300 graduates. Its cooperation with top corporations (Microsoft, Boeing, Amazon) in US offers students with numerous internship and employment opportunities [7].

\section{Teaching Management \\ Highly Valued by Both Parties}

The success of this program relies on great importance attached by both parties and joint efforts of their teachers. SZPT sees this program an important milestone of its international development, and holds several school affair meetings to discuss its promotion and recruitment. Leaderships of both parities have presented the opening ceremonies and graduation ceremonies in 2012, 2013, 2015 and 2016, and held friendly talks.

Persons in charge of Chinese affairs and the School of Management of CityU visit our school to examine joint achievements and conduct deep communication and cooperation every semester. Tom Cary, Vice President of the School of Management of CityU visited our school and held a short-term training for teachers in this joint program in 2014.

In March 2016, Fan Zhihang, a student of Sino-US Logistics Management in the School of Management enrolled in 2012 came back to share his experience in US with junior fellows during the Spring Holidays of CityU. The exchange meeting is packed with students where Fan mainly introduced his learning in CityU and notes for application. The study in CityU is tense and full of challenges as every semester has three and four courses at average. Students from around the world create a good climate to improve languages. To be well-prepared for future study in US, Fan encouraged fellow students to enhance English study while learning the professional courses. Thanks to this exchange meeting, students in the Sino-US class get a clear direction for future study, which will lay a good foundation for their study abroad after graduation.

Four backbone teachers of Sino-US cooperative majors from the School of Management and the School of Computer Engineering arrived in CityU in January 2017 and received training and study for a week to promote program and teaching quality. The delegation visited CityU's campus and training base, and communicated with faulty members and students of the US party.

Kurt Kirstein, Vice President of CityU visited our school in October 2017, and both parties discussed problems found during program running to promote its smooth operation.

\section{Recruit Top Students}

Since its launch four years ago, this Program has been highly recognized by students and their parents with gradually improved quality. The Program recruited 25 students in 2012, and admitted 31, 39, 42, 35 and 37 students through the college entrance examination during 2013-2017 respectively.

\section{Assign Excellent Teachers}

SZPT selected 19 teachers in this Program (8 teachers for the freshman and sophomore respectively, and 3 teachers for the junior), and 10 foreign teachers participate in this program (4 teachers for the freshman and sophomore respectively, and 2 teachers for the junior). Core courses taught by teachers from foreign educational institution account for $44.4 \%$ of total courses.

Currently, our logistics management has a faculty of 3 professors, 12 associate professors and 1 school -level gold teacher, 10 engineers, 2 senior logistics managers. Among them, 2 teachers are listed in the school-level "Thousand-Hundred-Ten Talents" Project, and $100 \%$ are double qualified. Top priority will be given to prominent teachers in this major and other excellent teachers for joining this joint program with City University of Seattle.

Our courses already opened to students represent superior teacher qualifications and sound teaching effects. For example, Thomas who teaches English listening and speaking, came from UK and was graduated from the School of Laws of Lancaster University. He is rigorous, teaches UK and US culture and understands learning habits of Chinese students. His lively and interesting class is highly appraised and popular among students.

\section{Arrange Special Persons for Management}

Our School of Management sets up a working group for this program, and Dean Dou Zhiming and deputy dean Shi Qiang hold the posts of team leader and deputy team leader respectively. Xiao Meng is 
assigned as the special manager of this program. Each class is arranged with one instructor and one class teacher for the management of program, teaching and students.

\section{Teaching Quality Management \\ Teaching Arrangement}

Over the three-year teaching, Chinese teachers are responsible for basic courses and professional basic courses (1,022 teaching hours), accounting for $49 \%$ of total planned teaching hours. Core professional courses provided by CityU are taught by teachers from the US party (1,064 teaching hours), accounting for $51 \%$ of total planned teaching hours. Courses introduced from CityU and core professional courses (1,064 teaching hours) take up $51 \%$ of overall courses.

CityU provides the syllabus of professional courses for this joint program, including course manual, unit description, and lecture outline, lesson preparation scripts for textbooks and units, as well as e-textbooks. SZPT offers related course outline related to cooperative majors, including course manual and unit description. Courses are taught in strict accordance with the course outline.

\section{Quality Management}

CityU participates in examination during teaching period. Based on requirements, some courses are examined in English, including speech, interview, and group work. Final examines include independent examines and collective exams.

Our school and CityU jointly establish three sets of document systems, including student archives, teaching archives and course archives. CityU provides documents related to course management and quality monitoring, and our school will be responsible for specific implementation in strict accordance with related documents.

\section{Social Assessment \\ Superior Style of Study}

According to reflection from teachers and students, students in this major study hard with clear objectives, and are more active for learning compared with students in other classes at the same grade. Sumali Wumaierjiang enrolled in 2012 have won universitylevel second-class scholarships for three times; Pan Yumeng have won university-level third-class scholarships for five times. Huang Fei enrolled in 2013 are winners of second-class scholarships for successive four times, third-class scholarship for one time, the title of Excellent Cadres and Excellent Award of Speech Contest; Zeng Difan has won third-class scholarship for successive three times and one two-class scholarship; Mai Chunhui enrolled in 2015 and Liu Yukang are rewarded with one two-class scholarship respectively; Zhou Xiangpeng wins one two-class scholarship and one third-class scholarship respectively; and Zeng
Yaole is the winner of third-class scholarship for two times.

\section{Sound Class Atmosphere}

Based on the student management system introduced from CityU, this major adopts selfmanagement for class to promote comprehensive development of students. The working principle is to cultivate compound, innovative talents with high quality and skills.

Various cultural and sports activities are conducted in after-class time, such as psychological counselling for freshmen with the theme of "we are like a family", design competition of class clothing, class show of sport meeting of college, theme week and class plan design competition. These activities have promoted class cohesion and self-management and selfservice conciseness of students.

\section{Promote School-running Level}

The international joint program will optimize educational resources, and promote efficiency and benefits of educational input. Through cooperation with CityU in aspects like mutual course selection, mutual recognition of credits, mutual recruitment of teachers and opening of common courses, our teachers in Logistics Management major broaden their international visions, and gain talent cultivation plans from US colleges. With two strategies of "introduction of foreign teachers" and "going-out of Chinese teachers", the international level among teachers in logistics management major is greatly improved. In particular, after the program is launched, over 10 professional teachers have visited US for investigation. There emerges a teacher team with international level. Some scholars get to understand study methods of international rules, which promote international academic exchange and cooperation.

\section{Promote Cultivation of International Talents with High Quality and Skills}

Students gain their professional capacities and comprehensive quality through this cooperative program, and gradually grow into application-based talents proficient in English with international vision. By June 2020, a total of 60 students have got the opportunity to go to CityU for learning and exchange, among them, all 60 students gained the diploma certificate of bachelor degree in Logistics Management of CityU, laying solid foundation for their career development. This joint program is highly affirmed by students and parents and achieves good social benefits.

\section{Suggestions and Future Directions of Sino-US Joint Program Strengthen Teacher Training}

For a better development of the program, it is suggested to assign more teachers to US for training to understand the talent training plan of CityU, meet 
corresponding teaching quality and management standards, and conform to related requirements of CityU.

\section{Expand Cooperation with CityU}

It is desired to strengthen cooperation in such fields as information exchange, course link, mutual recognition of credits and teacher training. In addition, we hope to assign more graduates to CityU for future learning, to improve joint level and add cooperative majors. Moreover, cooperative contents are expected to expand to scientific $R \& D$, introduction of new technology to deepen our cooperative relationship and achieve win-win outcomes.

\section{REFERENCES}

1. Bown. Education, skills and international cooperation: comparative and historical perspectives $[\mathrm{J}]$. Compare: A Journal of Comparative and International Education, 2020, 50(2).

2. Gómez-Batiste X, Lasmarías C, Amblàs J, Costa X, Ela S, Mir S, Calsina-Berna A, Espaulella J, Santaugènia $S$, Pujol R, Geli MG. Chair ICO/UVIC-UCC of palliative care at the University of Vic-Central University of Catalonia: an innovative multidisciplinary model of education, research and knowledge transfer. BMJ supportive \& palliative care. 2019 Dec 1;9(4):e33.

3. Jiang Y. Global Talent Cultivation against the Backdrop of International Cooperation for Education [J]. Scholar Community, 2017(01): 285 290.

4. Renfors SM, Veliverronena L, Grinfelde I. Developing tourism curriculum content to support international tourism growth and competitiveness: An example from the central Baltic area. Journal of Hospitality \& Tourism Education. 2020 Apr 2;32(2):124-32.

5. Roland G, Nicolas R. Improving school education in science, technology, engineering, and mathematics: practical methods and an international cooperation [J]. PAMM, 2018, 18(1).

6. Second International Workshop on Tethyan Orogenesis and Metallogeny in Asia (IWTOMA) and Silk Road Higher Education Cooperation Forum [J]. Journal of Earth Science, 2015; 26(2):1-2.

7. Yang L. The rise of China-U.S. international cooperation in higher education: views from the field. Higher Education. 2019; 78(1):189-191. 